extension of the area capable of supporting the crop. Pasture problems are being investigated both from the agricultural and the chemical point of view, special attention being paid to their mineral content and improvement by means of the introduction of superior species and strains.

Survey and classification of the various soil types in Australia forms a further branch of the work in the chemical section, and fertility problems, particularly in the irrigation settlements, are also being investigated. Entomological work has only been in progress since 1929 , but already much valuable in. formation has been obtained with regard to various pests of pasture, cereal and orchard crops. Diseases of agricultural crops inevitably form an important branch of the work of the Institute, and deficiency diseases due to a lack of some mineral element have also been successfully investigated. Breeding experiments with the view of securing varieties with improved resistance to fungus diseases form a natural corollary to the work of the plant pathology section.

Besides the land devoted to agricultural experiments, a certain area is reserved as a permanent park. Advantage has been taken of this to plant a portion as an arboretum, one section being used for indigenous, and another for introduced, species. The report includes a list, with abstracts, of the 141 papers published from the Institute during the years under review, reference to which will indicate the important results on widely different subjects which have already been obtained.

\title{
The British Pharmaceutical Codex
}

$\mathrm{T}$ HE Codex Revision Committee of the Pharmaceutical Society of Great Britain is issuing in the form of small monographs the reports of its sub-committees* which have been considering different aspects of the Codex in view of its revision this year. The next issue will contain about 300 monographs on crude drugs of vegetable origin of which less than seventy are included in the British Pharmacopœia.

The report of the Pharmacognosy Sub-Committee gives a summary of the principal standards for crude vegetable drugs, which have been accepted provisionally for inclusion in the new edition of the Codex : the standards of purity are based on determinations of foreign matter, alkaloid content, ash, extractive, etc., carried out in a manner similar to the corresponding tests of purity for the drugs in the Pharmacopoia. The report does not deal with the larger part of the sub-committee's work which is concerned with the revision of the descriptions, characters, constituents and commercial varieties of crude vegetable drugs.

The report of the Action and Uses Sub-Committee supplies descriptive portions for about fifty drugs, mostly of animal origin, including antitoxins, toxins

* The Pharmaceutical Society of Great Britain : Codex Revision Committee. Reports of Pharmacognosy Subcommittee (pp. 20 28.), of Action and Uses Subcommittee (pp. 14: 1s.6d.) and o Pharmacy Subcommittee (pp. 49:2s.6d.). The Pharmaceutical Press, 23 Bloomsbury Square, London, W.C.1. and gland products. Among the substances described are scarlet fever toxin and antitoxin, new tuberculin, antimeningococcal, antipneumococcal and antistreptococcal sera, gonococcal, pneumococcal and staphyloccecal vaccines, rennet, extracts of parathyroid and suprarenal cortex, œstrin, desiccated stomach and vitamin $A, B, C$ and D concentrates. Standards are suggested for the different preparations. In addition, the sub-committee has revised the "actions and uses" sections of about 1,000 monographs, although their recommendations are not included in this report.

The report of the Pharmacy Sub-Committee includes the principal new and revised formulæ, expressed in both metric and imperial systems, suggested for the formulary section of the Codex. In addition, according to the introduction to the report by the editor, Mr. C. E. Corfield, the sub-committee has worked out tests which it has recommended should be included to form B.P.C. standards for the different preparations. It has also recommended the inclusion of alcohol limits for the concentrated infusions, spirits and tinctures, as well as formulæ for a number of preparations from earlier pharmacopœias which are not included in the British Pharmacopœia 1932, but are still in more or less frequent demand. The reports are issued in the hope that useful comments on the suggested revisions will be received.

\section{Valve Conditions in the Internal Combustion Engine}

$\mathrm{M}$ AINTENANCE of the automobile engine of to-day is little more than a process of periodic adjustment and replacement, necessitated by wear in component parts. Accordingly any systematic study of the factors causing or influencing such wear will be followed with interest by users and manufacturers alike. In recent years, the Research Committee of the Institution of Automobile Engineers, Watergate House, York Buildings, Adelphi, W.C.2, has undertaken the investigation of wear occurring in various parts subjected to the trying temperature conditions existing in and about the combustion zone. This work has been particularly fruitful. Last year the Committee issued a report on "Cylinder Wear" which attracted considerable attention, and now it has published the results of its work on "Valve Seat Wear".

The first part of the present report deals directly with valve seat wear and describes the experimental technique adopted to discriminate between actual wear in the valve seat and distortion of the valve. Two types of valve material were used. With both, the rate of valve sinkage increased rapidly with increase in tappet clearance and, within the practical temperature range, with rise in temperature. In the one case, however, the valve sinkage was mainly due to seat wear, whereas in the other, it was almost entirely attributable to distortion or 'dishing' of the valve head. Tests with different widths of valve seat bring out the fact that wear is quite independent of seat area.

The important effect of temperature prompted an investigation of the factors influencing exhaust valve and seat temperatures. The results obtained are set out in the second part of the report, and show the influence upon valve and seat tempera- 
tures of engine speed, length of valve guide, diameter of valve stem, width of seat, fuel and mixture strength, ignition setting, and cooling water outlet temperature. These results are all interesting and some should prove of real practical use. One point to be particularly noticed is the statement that maximum engine temperatures were obtained when using normal mixtures with optimum ignition advance, a result quite contrary to the common belief that retarded ignition and weak mixtures give rise to overheating.

\section{Sound Recording for the Cinematograph}

T HE improvement in the quality of recorded sound during the past five or six years has been very rapid. During that time the silent film has been almost entirely superseded by the 'talkie' in the cinema. Dr. C. E. K. Mees, in the Sir Henry Trueman Wood Memorial Lecture delivered before the Royal Society of Arts on May 16, said that the introduction of sound recording to the cinema has influenced every part of the motion picture industry. While it will be readily appreciated that the various developments of the mechanisms for recording and reproducing pictures and sound have in themselves been very extensive, striking changes have also been made in other things, such as the design of theatres and the kind of play which may successfully be filmed.

The detail of sound recording and reproduction for the cinematograph may be divided into several sections : (1) Conversion of sound to electrical pulses ; (2) modulation of light intensity by the electrical pulses; (3) photographic recording of the light fluctuations; (4) light fluctuations reconverted to electrical pulses ; (5) electrical operation of the loud speaker. Much of this long chain of operations is concerned with electrical apparatus, but the photographic part differs in no essential way from the ordinary procedure of taking a snapshot, making and projecting a lantern slide. Each of the photographic processes calls, however, for very much more accurate control than is necessary for mere picture-making. Very extensive investigations have been made of the whole subject. These have covered many points already broadly understood, but the new work has been necessarily much more thorough.

The influence of the new knowledge gained is manifest in the improved quality of the sound in the theatres : there is less distortion and less 'ground noise'. Of the first of these it can only be said that constant research on the problems of making and matching negative and positive, and studying wave form reproduction, are gradually pushing the quality beyond its already high level. It seems, however, that little reduction in ground noise is to be expected from diminishing the grainy quality of the photographic material; the presence of minute scratches, dirt particles, etc., which are inevitably formed when the film is handled, is generally more than enough to counterbalance any decrease in graininess. The reduction of ground noise is being accomplished by modifying the recording apparatus so that the influence of flaws on the film is allowed to operate fully only when the sound to be recorded is loudest : the true sound record then masks the trouble.

The researches already carried out have necessitated the construction of much special apparatus and the development of special technique. Now that these are available, progress is likely to be even more rapid.

\section{University and Educational Intelligence}

London.-The following degrees have recently been awarded: D.Sc, in chemistry on H. Martin (Imperial College-Royal College of Science) for thirty-one published works on the "Elucidation of the Mechanism of the Toxic Action of Insecticides and Fungicides used for the Control of Crop Pests and Diseases"; D.Sc. in physiology on Dame Anne Louise McIlroy (University professor of obstetrics and gynæcology at the London (R.F.H.) School of Medicine for Women) for a thesis entitled "Researches upon the Prevention and Treatment of Asphyxia in the New-born" (Med. J. and Record, Nov. and Dec. 1933); D.Sc. in zoology on Ethelwynn Trewavas (private study) for published works entitled (1) "The Hyoid and Larynx of the Anura", (2) "Enteropneusta", (3) "A Revision of the Cichlid Fishes of the genus Lethrinops, Regan", (4) "Scientific Results of the Cambridge Expedition to the East African Lakes, 1930-31. II. The Cichlid Fishes", (5) "A Contribution to the Classification of the Fishes of the order Apodes, based on the Osteology of some rare Eels", (6) "On the Structure of two Oceanic Fishes, Cyema atrum, Gunther, and Opisthoproctus soleatus, Vaillant", together with three conjoint subsidiary contributions.

The American system of radio broadcasting was criticised in an address to the Ohio Radio Institute on May 2 by Levering Tyson, director of the National Advisory Council on Radio in Education. The actual situation is that while, from the engineering point of view, there has been remarkable progress, the programmes have no greater cultural value than before 1927 when a licensing authority was established. This authority has tended to crystallise the status quo so that the fundamental concept of broadcasting as a public service has been side-tracked and it remains an individualistic enterprise for private gain. The problems of educational broadcasting are no nearer solution than in 1929 when Secretary Wilbur appointed a committee to investigate them, and the number of educational stations has decreased steadily until to-day there are only a few dozen. Mr. Tyson anticipates that an effort will be made by the industry to put its house in order but that advertisement will continue to be its financial basis. He looks for a gradual assumption by the State of responsibility for establishing certain public services within or parallel to the industry but he holds that "you can't force intellectuality down democracy's throat unless it opens wide its mouth. So far its teeth have been tightly clenched". The address is reproduced in School and Society of June 30 .

Education in Kent, 1928-1933, is reviewed by the director, Mr. E. Salter Davies, in a report recently published by the County Education Committee. The administrative machinery was subjected to a severe strain in 1931, when expenditure had to be drastically restricted, and withstood the strain well, thanks to the elasticity and resiliency produced by a happy co-operation of its component parts and broad. minded and vigorous leadership. There was a notable rapprochement between the educational system and the requirements of industry. One of many instances of this is to be found in the ample provision for 